\title{
Proposed Measures to Mitigate Energy Interruptions in Residential Sector
}

\author{
Abdullah M. Al-Shaalan \\ EE Department, College of Engineering, King Saud University, Riyadh, KSA \\ Email: shaalan@ksu.edu, sashaalan123@gmail.com
}

How to cite this paper: Al-Shaalan, A.M. (2017) Proposed Measures to Mitigate Energy Interruptions in Residential Sector. Journal of Power and Energy Engineering, 5, 5063.

https://doi.org/10.4236/jpee.2017.56005

Received: May 1, 2017

Accepted: June 17, 2017

Published: June 20, 2017

Copyright $\odot 2017$ by author and Scientific Research Publishing Inc. This work is licensed under the Creative Commons Attribution International License (CC BY 4.0).

http://creativecommons.org/licenses/by/4.0/

\begin{abstract}
This study investigates and analyzes the electric energy interruptions impact upon the residential sector in Riyadh city, the capital of the Kingdom of Saudi Arabia (KSA) resulting from severe power outages. The study results show that this sector which constitutes about $54 \%$ of the Saudi Electric Company in the Central Operating Area (SEC-COA) will suffer enormous tangible and intangible losses should occur in specific times, seasons and last for longer durations. The results obtained for the costs of these energy interruptions reveal a time-dependent non-linear outage cost variation. In order to reduce these energy interruptions and hence mitigate their adverse effects and consequences, the study proposes proper practical measures and solutions without compromising the consumers' needs and convenience.
\end{abstract}

\section{Keywords}

Energy Interruptions, Residential Sector, Losses, Severe Power Outages

\section{Introduction}

Electric service interruptions occur when system capacity, due to severe power outages, is insufficient to meet the system load levels. During these periods of inadequacy, outage costs will be borne by the utility, its customers and perhaps, by the entire society. The utility outage costs include loss of revenue, loss of future sales and increased repair expenditure and maintenance. These costs usually form only a small part of the total outages costs. The greater part is that borne by the consumers. The outage costs depend on many factors and situations, some of which are discussed in the following sections.

The problem of exploring energy interruptions impact upon the consumers depends on many factors and situations as well as the perceived effects of an interruption when a consumer needs critically electric energy but is deprived to 
attain it. There are different classes of consumers; each will tolerate loss of service differently. For instance, if the interruption occurs to an industrial user during the time of production process, he will certainly incur a great loss but it can be alleviated by some means of early warnings, available standbys, or compensations. For a commercial consumer, the interruption occurrence may cause inconvenience to that user who is either forced to close until power is restored or operate his own alternative means, particularly, supermarkets containing food freezers. For the residential consumer, he will suffer disruption of domestic activities, loss of leisure, food spoilage, and health hazards. Also he will endure a great deal of hardship if an interruption occurs during evenings, hot summer days, month of holy Ramadan, etc. that will cause distress, discomfort and anxiety.

The difficulty associated with estimating residential losses, resulting from severe power outages, is due to the fact that the activities of this sector are not productive and most of its outputs are consumed within the household premises and cannot be valued in the market. Interruptions may disrupt domestic activities such as cooking, washing, vacuum cleaning, air conditioners, lighting, entertainment, social guest gatherings etc. However, residential consumer may incur tangible losses such as foods spoilage, paying extra expenses and intangible losses in terms of inconvenience, discomfort, and anxiety.

If an interruption continues or spreads to a larger subset of society, the society losses will tend to increase in a non-linear trend. So energy conservation strategies may constitute a preferable measure to be adopted and applied in order to curb these energy curtailments to the least tolerable limit. The residential sector in the city of Riyadh has been selected as a practical case to conduct this study as it represents the major share of energy consumption.

\section{Review of Existing Studies}

To review some of existing studies, Kristina [1] discussed the massive electric power outage that occurred in the northeastern United States on August 14-15, 2003. They estimated the losses associated with that severe power outage affecting residential consumers for longer durations. Manikya [2] utilizes a practical radial distribution system database in the development of individual consumer sector and establishes composite consumer damage functions for combinations of all consumer classes. Snead [3] discussed the issue of energy efficiency and conservation in the residential sector and showed that energy efficiency can be targeted to reduce peak demand. Vivien et al. [4] presented an empirical work that has been done at an international level data in order to test for the relationship between energy consumption and income per capita at the household level. Layton [5] used a survey to households' willingness to pay to avoid unexpected interruptions in electricity service. In this survey, the author used a statistical approach that is defined as a function of household characteristics, outage attributes and outages history. Benders [6] developed a web-based tool that addresses direct as well as indirect energy requirements. This tool was tested with a 
sample of 300 households, resulting in a direct and indirect energy reduction of about 31\% compared to total energy consumption. McMakin [7] described energy-conservation campaigns applied at two military installations where residents do not pay their own energy bills. Marshall [8] used energy-conservation programs that are focused on the residential sector with more variables that affect household energy conservation and lead to more-effective consumer energy conservation. Fuji [9] developed a model that explains household choice of electricity conservation modes. The model is based on the premise that households will adopt those conservation modes that yield benefits greater than perceived costs. Yoshiyuki [10] evaluated energy conservation methodologies for the residential sector by employing a model that simulates city-scale energy consumption in the residential sector by considering the diversity of household and building types. HiChun [11] indicated that, as energy conservation can be realized through changes in the composition of goods and services consumed, there is a need to assess indirect and total household energy requirements. Ghaddar [12] showed that energy conservation measures on buildings have a significant role to play in reducing the burden of the energy bill on the Lebanese economy. The residential sector is the main sector that energy measures can be applied to. Taniguchi [13] performed modeling of energy consumption by residential sector of 20 Japanese cities modeled at the city-scale and the model households were classified into 228 categories based on the family size and building type. He evaluated the effectiveness of energy conservation measures, such as improving energy efficiency of home appliances, improving heat insulation of buildings, changing preset temperature, and all family members watching TV together. Xu Peng [14] measured, in laboratory and in site, the thermal behaviors of specimens and an upgraded prototype residential building in China. The research showed that the proposed insulation system can save as much as 50 percent of the energy through it. The field measurements showed that $30 \%$ reduction of the overall energy consumed by newly-built buildings. Abrahamse [15] reviewed and evaluated the effectiveness of encouraging households to reduce energy consumption and some important issues cloud these conclusions, such as methodological problems.

\section{Work Objective and Proposed Methodology}

The review of the preceding studies reveals that their authors assessed the energy conservation in the residential sector without explicitly considering it as a hedge against power outages and a remedy to energy ceases. Hence, it is the author's impression, that there is a modest attention that was given to the advantageous and rewarding correlation between coherent energy conservation and least outages occurrences. Therefore, the objective of this work is to narrow this existing gap in the present studies. Hence, the first step of this endeavor is to explore, from the consumer's perspective, the adverse effects of the energy interruptions that reflect enormous damages (tangible and intangible) to the residential sector in the city of Riyadh. The second step is to propose, adopting and employing 
energy conservation strategies in order to overcome these damages and ensure energy continuity and preservation as well as saving in consumption costs. To fulfill these two essential steps, the following processes have been established:

a) Using a consumer survey which is considered to yield practical and definite results that can estimate real impact of energy shortages upon residential sector. It is the author's opinion that the most suitable estimate of outages losses and costs is the consumer's assessment based on his own perception to these consequences during power outages and types of preparatory actions or willingness-to-pay he may undertake to avoid such outages or, at least, mitigate their effects.

b) Developing a mathematical model in order to motivate the survey work and define the key variables in the survey database and supplement for any erroneous or missing data provided by the individual respondent.

\section{Results and Discussions}

The data used in this study is based on 454 responses to the residential survey out of 626 distributed questionnaires. The survey involved arbitrary samples of residential consumers in Riyadh city (employees, traders, workers, and academia). The respondents were asked to provide information concerning dwelling types, income sources and size and number of persons living in the household (Q1 \& 2), their activities during evening leisure times (Q3), their experience with service outages during the past two years (Q4), measuring their level of hardship of being unable to use their major appliances during power cease (Q5), assessing their losses resulting from lasting outages and proposing certain preparatory actions to lessen their effects (Q6), their average monthly energy consumption and their attitude regarding the prevailing tariff (Q7), the extent of the consumer willingness-to-pay in order to avoid service interruptions (Q8). Finally, exploring existing energy conservation programs that may consumers adopt and use in order to reduce the occurrences of power outages and hence alleviate their adverse consequences (Q9).

\subsection{Levels of Hardship with Energy Interruptions}

To explore the extent of respondents' discomfort, anxiety and adversity during energy interruptions, they have been asked to give, based on a scale varying from 0 (no hardship) to 5 (extreme hardship), their level of hardship of not being able to use major electrical appliances such as kitchen devices, washing machines, air conditioners, lighting. Their responses are portrayed in Figure 1. It is noticed from the figure that the most critical devices that the residential consumers will not be able to use, should an outage occur, are mainly air conditioners followed closely by loss of lighting and less closely by kitchen facilities and washing machines.

\subsection{Consumers' Reaction against Daily Outage with Lasting Durations}

The respondents' reactions towards frequent outages occurrences of lasting du- 


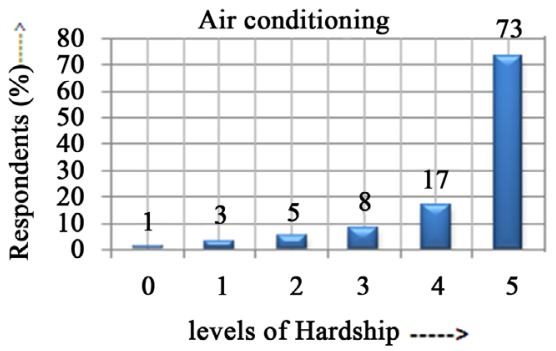

Kitchen

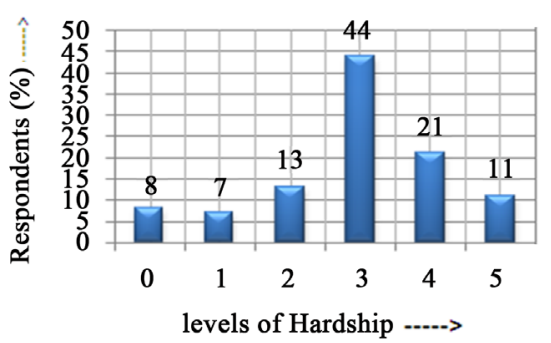

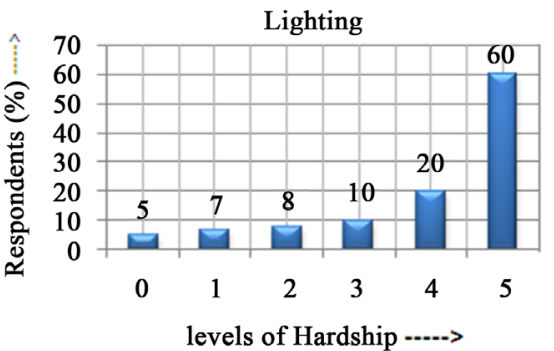

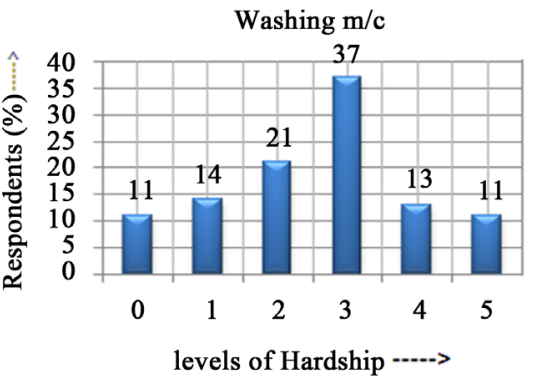

Figure 1. Variation of household hardship regarding inability of using major appliances during energy interruptions.

rations were also sought. These occurrences were assumed to be in the summer season and after midday where the use of air conditioners in a country like Saudi Arabia is mostly needed. The duration of these interruptions were suggested to last 20 minutes, 1 hour, 4 hours and 8 hours. The results are shown in Figure 2 which depicts the respondents' annoyance and irritation that is rapidly rising with extended service interruptions.

\subsection{Cost Estimation Based on Consumer's Perception and Willingness-to-Pay}

Most of outages effects, as are noticed above (Figure 1 \& Figure 2), are intangible and cannot be assessed in terms of monetary values and a single complete measure of the worth of reliability of supply to residential users is difficult, if not impossible, to obtain. The question which is appropriate to be asked is: What set of preparations and precautions a residential consumer should adopt as a criterion to ensure supply continuity and quality worth? The answer depends on practical and theoretical structure of the analyses. In general, it is the author's opinion that one of the most suitable estimates of reliability worth is the consumer's preparatory actions during power outages and his willingness-to-pay to avert their occurrences. This approach is practically sound and more related to the perception of the residential consumer and to his energy requirements. Therefore, to seek the consumer's readiness and type of preparatory actions that he intends to undertake against possible power outages and energy interruptions, respondents were directed to suppose that they are told by their local electric company that unexpected power outages will occur daily in summer time for various durations and asked to predict which action(s) they might take in preparation for the outages (Question 6). The costs quoted in the list of actions are used to compute an estimate of the cost of preparations that respondents in- 

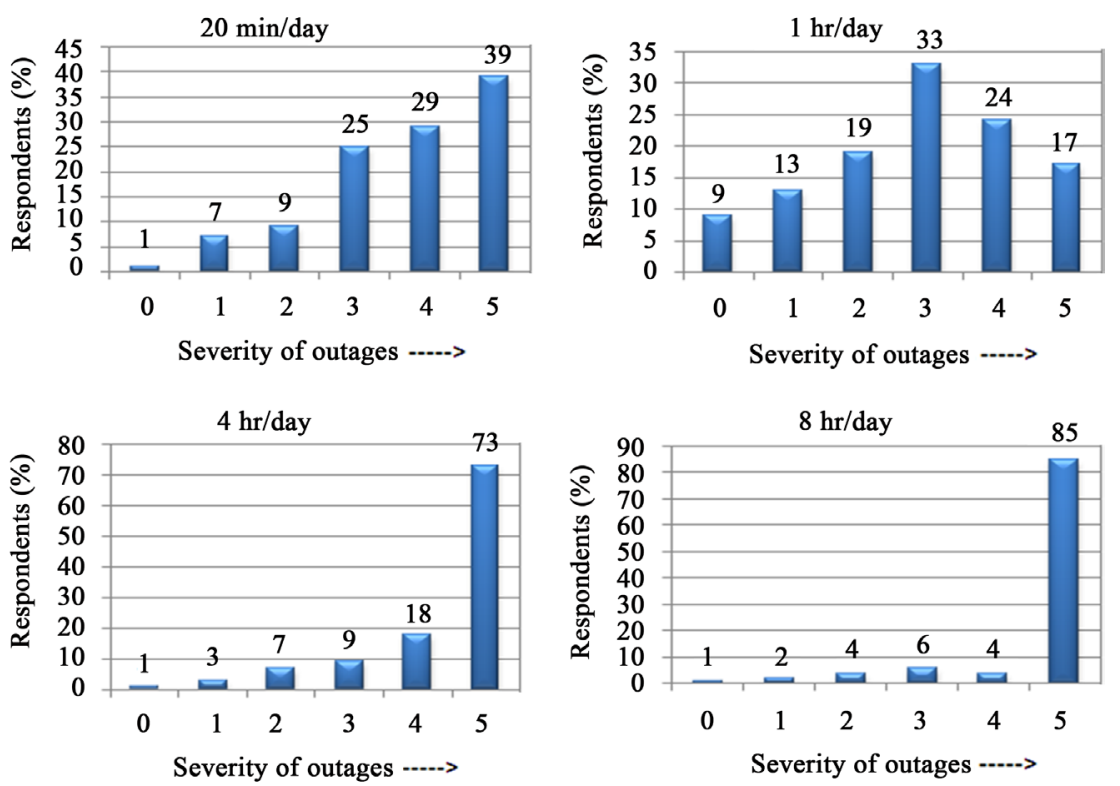

Figure 2. Variation of hardship with outages occurrences and lasting durations.

dicate that they are willing to undertake to eliminate or, at least, to mitigate the adverse effects of the outages. Also, the survey explores to what extent they are willing to pay to avert service cessation. Therefore, it is suggested (Question 8) that the power system has become subject to more frequent power outages. To increase system reliability, the company may add generating units and/or reinforce its network facilities which may result in tariff increase. Hence, the question postulates daily power outages in summer period for durations of $20 \mathrm{~min}$ utes, 1 hour, 4 hours, and 8 hours. A range of possible tariff rate increases is proposed and the consumers were asked to perceive and appraise the possible damage resulting from service interruptions and consequently discern an appropriate tariff rate increases based on its prevailing present structure. The data reported by the respondents is exhibited by Figure 3. The survey results show that a significant number of respondents were willing to pay higher rate for even up to $20 \%$ above the cost of the normal charge to avert prolong outage durations. The willingness-to-pay, however, becomes less when more rate increase is suggested or less frequent outages are proposed. The costs perk Wh for various durations estimated as above is probably the most meaningful for the residential user group and for comparison with other studies as well as for planning purposes.

\subsection{Outage Cost Estimation by Using Survey Method and Mathematical Model}

\subsubsection{Outage Cost Estimation by Using Survey Approach}

In this work, two main approaches were considered and are presented. The first one is concerned with using a survey methodology based on rate increase, wherein respondents were asked to what extent increase in tariff rate they are willing-to-pay to avoid outages for various outages durations. The direct worth evaluation approach asks consumers to place a monetary value on the effects of 


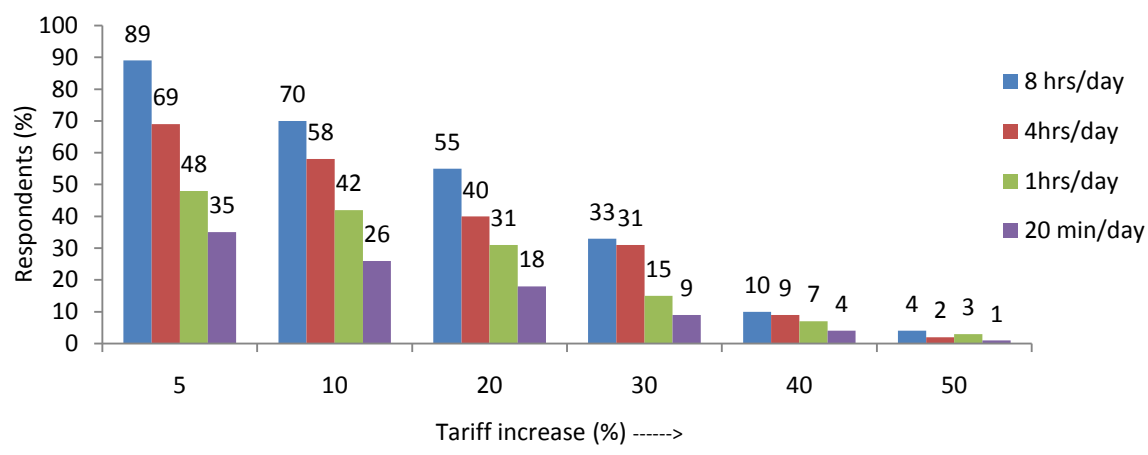

Figure 3. Suggested traff rate increase with outage durations.

certain interruptions scenarios or to assess the worth to them of not having to experience an interruption. The average value of the maximum amount per month that the respondents were willing to pay for less severe outages (interruptions) occurrences is based on their average monthly energy consumptions $(\mathrm{kWh} / \mathrm{mo}$.) and invoice payments $(\mathrm{SR} / \mathrm{mo}$.) in summer season. This approach may suffer from the difficulty that residential respondents encounter when attempting to give meaningful answers to direct evaluation questions. This difficulty stems from the lack of respondent experience with markets in which intangible benefits, such as electric service reliability, are exchanged as a commodity.

\subsubsection{Outage Cost Estimation by Using a Mathematical Model Approach} Another approach which has been developed and used is based on a mathematical model. This model can decrease the size of the problem intricacies associated with consumer lack of experience in rating the worth of service adequacy, quality and continuity. Now the model can be derived as shown in the coming part.

Consider a typical household that maximizes utility over some period of time. Utility $U$ is expressed as a function of activity type $D$ that cannot be enjoyed without electricity and income $K$ (net of expenses incurred to enjoy the activity, which represents all other consumption):

$$
U=U(D, K)
$$

Next, activity type $D$ is specified as a function of inputs, time $t$ (hours), electricity consumption $c(\mathrm{kWh})$, flow of services $s$ from the stock of electricity using air-conditioner, lighting, TV etc., represented by $z$.

$$
D=D(t, c, s, z)
$$

Furthermore, $c$ and $s$ may be written as functions of the stock of electricity using capital $i$, the value of appliances annuitized over their useful life, and of time $t$ which is a measure of intensity use. Therefore, $c=c(i, t)$ and $s=s(i, t)$. The household budget constraint may be written as:

$$
K=w(H-t)-p \cdot c-b \cdot i-f \cdot z
$$

where $w=$ effective hourly net income earning rate; $H=$ maximum feasible number of hours of work in the time period; $p=$ mean price for each $\mathrm{kWh}$ of consumed electric energy; $b=$ equivalent income foregone for each unit of $i$ in 
the same period; $f=$ cost for each unit of other inputs $z$ used.

Maximizing utility subject to the linear budget constraint is equivalent to unconstrained maximization of the expression:

$$
U=U(D, K)-\lambda\left[H-t-\frac{1}{w}(K+p \cdot c+b \cdot i+f \cdot z)\right]
$$

The following equations indicate the first-order (necessary) conditions.

$$
\begin{gathered}
\frac{\partial U}{\partial t}=\frac{\partial U}{\partial D}\left[\frac{\partial D}{\partial t}+\frac{\partial D}{\partial c} \cdot \frac{\partial c}{\partial t}+\frac{\partial D}{\partial s} \cdot \frac{\partial s}{d t}\right]+\lambda\left[1+\frac{p}{w} \cdot \frac{\partial c}{\partial t}\right]=0 \\
\frac{\partial U}{\partial i}=\frac{\partial U}{\partial D}\left[\frac{\partial D}{\partial c} \cdot \frac{\partial c}{\partial i}+\frac{\partial D}{\partial s} \cdot \frac{\partial s}{\partial i}\right]+\frac{\lambda}{w}\left[p \cdot \frac{\partial c}{\partial i}+b\right]=0 \\
\frac{\partial U}{\partial z}=\frac{\partial U}{\partial D} \cdot \frac{\partial D}{\partial z}+\frac{\lambda}{w} \cdot f=0 \\
\frac{\partial U}{\partial K}=\frac{\partial U}{\partial K}+\frac{\lambda}{w}=0 \\
\frac{\partial U}{\partial \lambda}=-\left[H-t-\frac{1}{w}(K+p \cdot c+b \cdot i+f \cdot z)\right]=0
\end{gathered}
$$

Multiplying Equations (5), (6), (7) by $d t$, $d i$, and $d z$ respectively and summing the three resulting equations, and rearranging terms yields:

$$
\begin{aligned}
& \frac{\partial U}{\partial D}\left[\left(\frac{\partial D}{\partial t}+\frac{\partial D}{\partial c} \cdot \frac{\partial c}{\partial t}+\frac{\partial D}{\partial s} \cdot \frac{\partial s}{d t}\right) d t+\left(\frac{\partial D}{\partial c} \cdot \frac{\partial c}{\partial i}+\frac{\partial D}{\partial s} \cdot \frac{\partial s}{\partial i}\right) d i+\frac{\partial D}{\partial z} d z\right] \\
& +\frac{\lambda}{w}\left[\left(w+p \cdot \frac{\partial c}{\partial t}\right) d t+\left(p \cdot \frac{\partial c}{\partial i}+b\right) d i+f \cdot d z\right]=0
\end{aligned}
$$

Simplifying further:

$$
\frac{\partial U}{\partial D} \cdot d D+\frac{\lambda}{w}(w \cdot d t+p \cdot d c+b \cdot d i+f \cdot d z)=0
$$

Dividing Equation (11) by Equation (8) yields an expression involving the willingness-to-pay ( WTP) for electricity dependent activity, keeping utility constant as derived from the consumer's long run decision:

$$
W T P_{K D} \cdot d D=w \cdot d t+p \cdot d c+b \cdot d i+f \cdot d z
$$

where

$$
W T P_{K D}=\frac{\partial U}{\partial D} / \frac{\partial U}{\partial K}=-\left.\frac{\partial K}{\partial D}\right|_{U}
$$

By definition, $W T P_{K D}$ measures the marginal equivalent monetary value of electricity-dependent activity; that is the tariff increase that the consumer is willing to pay to just compensate for his lost activity due to electric service interruptions. Consider the effect of an unexpected outage during the evening when the family is enjoying activity type $S$. During the outage, it can be argued that $c, i$ and $z$ depend only on $t$. This assumes a coherent type of relation between $i$ and $d z$. For example, in any considered short period of time, electricity use may be linearly proportional to the time. Therefore, it is possible to write:

$$
c=\varphi(t)
$$


Using Equation (14) to evaluate Equation (12), and replacing $d D$ by $\Delta D$, and so on:

$$
M W T P_{K D} \cdot \Delta D=\left(w+p \cdot \frac{\partial \varphi}{\partial t}\right) \cdot \Delta t+b \cdot \Delta i+f \cdot \Delta z
$$

Thus, the left side of Equation (15) represents the overall welfare decrease because of an incremental loss of activity $\Delta D$ resulting from the unexpected outage of duration $\Delta t$, the right side measures the value of the inputs necessary to produce the activity. The term $(b \cdot \Delta i)$ is interpreted as representing the value of the input of electricity-using equipment that is foregone during the outage. If the income foregone in each period $(b i)$ is uniformly distributed over the activity period $t$ during which the equipment is used, then the average value of appliance input for every unit of activity time is bil $t$, and therefore

$$
b \cdot \Delta i=b \cdot(i / t) \cdot \Delta t
$$

The domestic electricity consumption cost will be reduced by the amount $p \cdot(\partial \varnothing / \partial t) \cdot \Delta t$ from $\mathrm{kWh}$ not used during the outage. Therefore, the net incremental welfare loss or outage cost $(O C)$ can be written as:

$$
\begin{aligned}
O C & =W T P_{K D} \cdot \Delta D-p \cdot(\partial \varnothing / \partial t) \cdot \Delta t \\
& =w \cdot \Delta t+b \cdot \Delta i+f \cdot \Delta z
\end{aligned}
$$

Equation (17) measures the welfare change caused by an incremental change in the availability of electricity-dependent activity $\Delta D$, in terms of the value of the inputs: $\Delta t, \Delta i, \Delta z$ which are required to produce this activity.

It is worth mentioning that the difficulties of obtaining data on using any type of electrical appliances during activity time will usually far outweigh any resulting refinement to the basic estimate of outage cost that is derived purely on the basis of more readily available income data. Therefore, in practice, the following expression may be used as a reasonable approximation to Equation (17):

$$
\Delta O C \approx w \cdot \Delta t
$$

In practical terms, the energy interruptions and excessive energy consumption can be envisaged as a coherent correlation. This correlation can be utilized in attempting to reduce power outages by embracing and applying effective and practical energy conservation measures that can reduce the occurrences of these power outages causing energy interruptions and allow the consumer to fulfil his domestic duties and enjoying leisure times and practising social and ceremonial activities.

\subsection{Outcomes of Both Survey Approaches and Mathematical Model Approach}

Results Estimations of both approaches are shown in Table 1 and plotted in Figure 4 for comparison reason. The curves show some discrepancy which may be ascribed, in the questionnaires results, to the infrequent outages occurrences and subsequently less enthusiasm on part of consumers to respond to outages in buying emergency items or taking any precautionary actions. The model 
Table 1. Variation of outages cost with outage duration.

\begin{tabular}{cccc}
\hline \multirow{2}{*}{ Outage durations } & \multicolumn{3}{c}{ Outages cost (SR/kWh) } \\
\cline { 2 - 4 } & Survey estimate & Model estimate & Predicted estimate \\
\hline 20 min. & 0.23 & 0.34 & 0.28 \\
1 hour & 0.52 & 1.24 & 0.69 \\
4 hours & 4.00 & 10.41 & 0.71 \\
8 hours & 99.80 & 140.10 & 121.43 \\
\hline
\end{tabular}

estimates seem to be higher and this also could be attributed to the electricity-dependence weight embodied in the estimate due to the link between the use of energy and the per capita income. Both curves demonstrate clearly the time-dependent and the non-linear nature of the outages cost that probably may reach prohibitive limits should outages lasted and extended for longer durations (see Figure 5).

\section{Comparison of Results with Other Similar Studies}

The cost estimation of energy cease as SR/kWh for the residential sector, shown in Figure 6, was evaluated for the purpose of this study and also to be conveniently compared with other similar time durations studies. Figure 4 portrays results of studies conducted in some countries including Riyadh study. Riyadh results, compared with those other results, seem to yield rather lower estimates. This can be interpreted as the methodology is in essence, based on the actual payable tariff. The Saudi government heavily subsidizes the electric sector and the customer pays only a reasonable part of the total cost. The noticeable diversities in these estimations seen in the figure can be attributed to variations in systems characteristics, the non-linear nature of outages costs, and the different modelling techniques employed.

\section{Conservation as a Hedge against Energy Interruptions}

There are immense efforts that have been spent (and still on-going progress) by various governmental and private entities in the KSA. In this last section, the Author will try, in a brief, to recap and enlighten these entities activities regarding their electricity conservation endeavors. The ministry of Water and Electricity (MWE) prepared an extensive long-range national electricity conservation plan targeting to save up to $30 \%$ of nation-wide energy consumption at the end of year 2030. Also, the MWE launched several energy conservation campaigns in order to raise the awareness at the consumers for better electric energy utilization and conservation. The Saudi Arabian Standards Organization (SASO) prepared national standards, to be complied by the manufacturers and importers, specifying the minimum efficiency requirements in some of popular domestic electrical appliances (i.e. air-conditioners, refrigerators, washing machines, dryers and chillers). ECRA (Electricity \& Cogeneration Regulatory Authority) organized several workshops for load management strategies and energy con- 


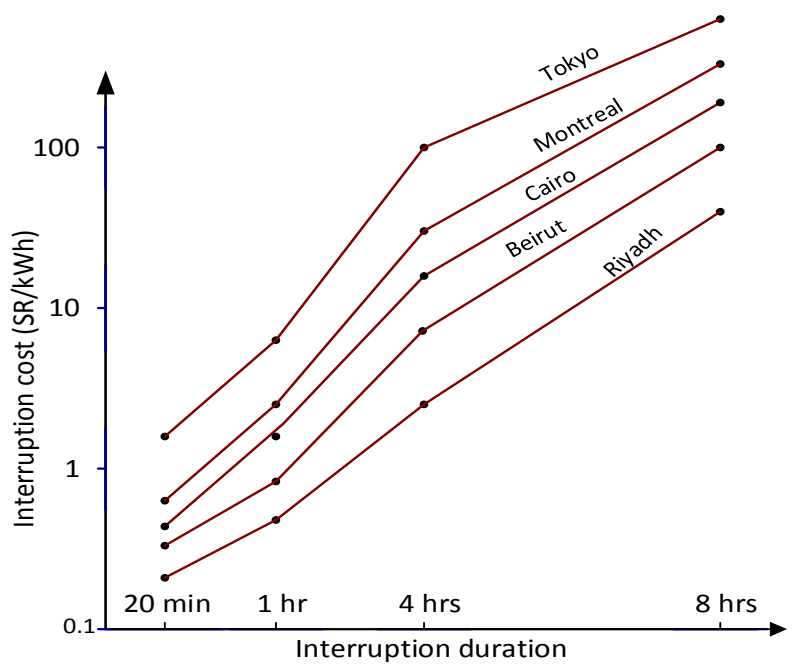

Figure 4. Comparison of Riyadh city outages cost with other world.

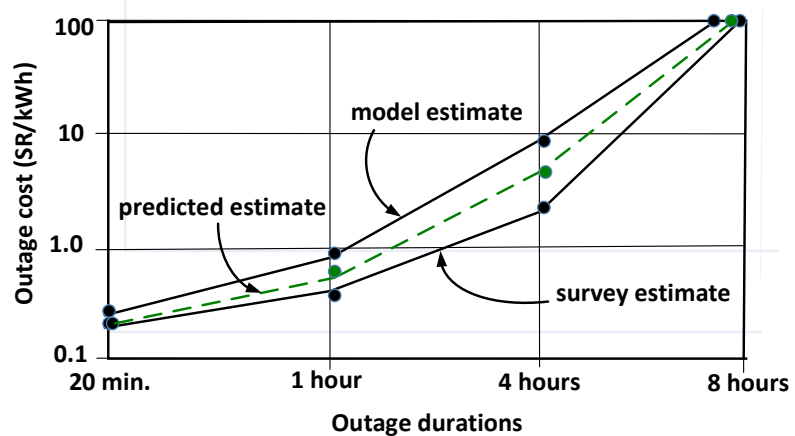

Figure 5. Variation of outage cost vs. outage duration.

servation. ECRA also, is responsible of structuring the tariff that can balance between the costs of energy production and consumption. Ministry of Education introduced the energy conservation principles in students' early education syllabus. The Saudi Electric Company (SEC) spread wide-range of publications and organized and participated in various programs aiming at promoting energy efficiency and conservation measures among its customers.

Benefitting from the opportunities of his elongate cooperation, collaboration and consultation with all the aforesaid entities, the Author was entitled and be able to gather and compile information for building Figure 6. This figure can be interpreted as follows: A group of residential consumers are selected among the SEC-COA customers with their readily available data extracted from the company records and consumers survey (such as income, connected load, energy consumption, monthly billing, frequent outages occurrences causing energy interruptions and their costs).

It is evident from the figure that, when the consumer exceeds his normal consumption (C-A) and passing through the normal and expected outages (C-B) at the point $\mathrm{A}$ (severe outage threshold) towards $\mathrm{D}$, he will then start experiencing severe outages occurrences initiating at point $B$ and escalating in a fast (logarithmic) manner to the point $\mathrm{D}$. 


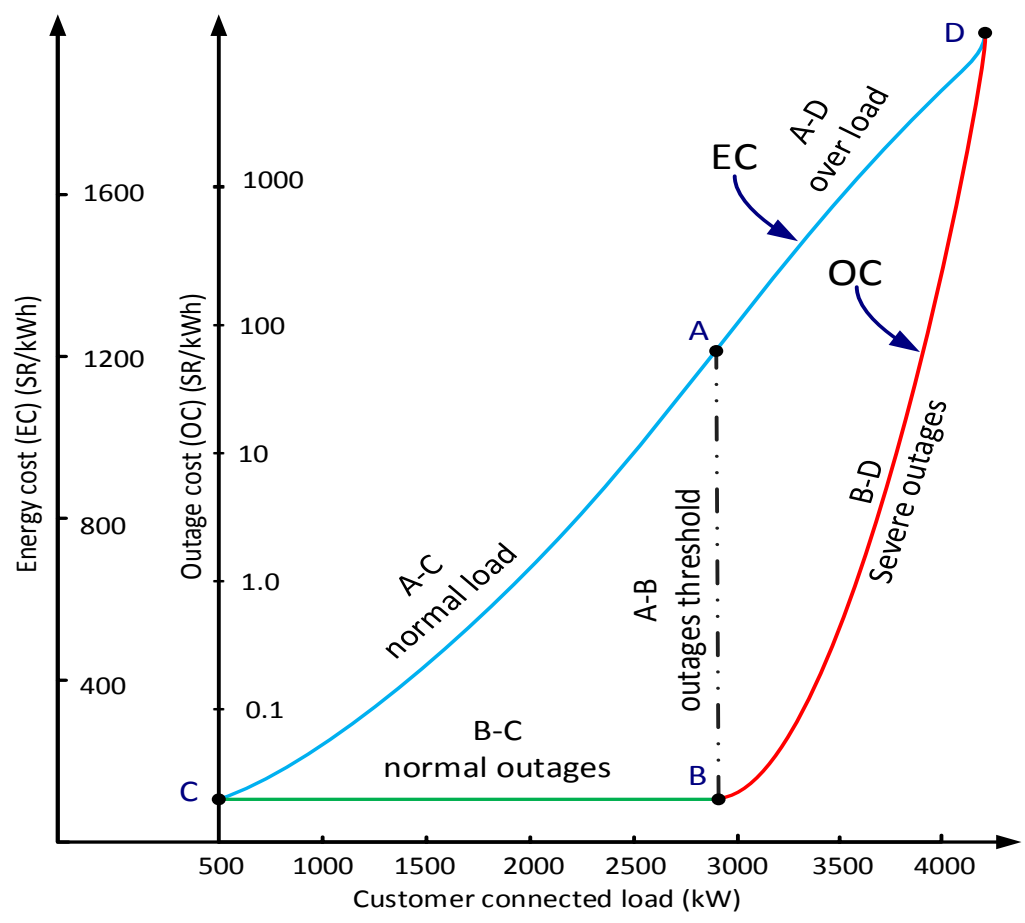

Figure 6. Limits between energy consumption cost and outage cost.

It was asserted in interpreting Equations (15) and (18) that the energy interruptions and excessive energy consumption can be envisaged as a coherent correlation. This correlation can be utilized in attempting to reduce power outages by embracing and applying effective and practical energy conservation measures that can reduce the occurrences of these outages and allow the consumer to fulfil his domestic duties and enjoying leisure times and practising social and ceremonial activities.

\section{Conclusions}

This work presents results of a study conducted to assess the perceived tangible and intangible losses and costs incurred by the residential sector in the city of Riyadh due to severe electric power outages that lead to energy interruptions and curtailments. It has focussed on the implementation and utilization of practical and theoretical tools for evaluating essential factors for reducing power outages and energy interruptions based on explicit consideration of consumer perception and evaluation to the interruptions impacts and consequences. The results reveal that these outages result in consumer's deprivation from domestic activities, social ceremonies, usage of certain essential appliances and food spoilage. These outages, naturally, cause consumer's discomfort, distress and anxiety of which are intangible losses and cannot be quantified in monetary values. Two approaches have been developed and utilized. The first one is based on a consumer's survey to estimate his perceived costs if outages occur in specific periods and last for longer durations and also based on his "willingness-to-pay" opinion to avoid these outages consequences. The second approach focussed on devel- 
oping a mathematical model to complement the survey approach as this model can decrease the size of the problem complexity associated with consumer lack of experience in evaluating and assessing the worth of service reliability and quality.

One major contribution of this work is manifested in the development of useful tools for system planners that enable them to incorporate consumer perceptions and preferences in their assessment. Another contribution of this work is exhibited in the compilation of residential cost of outages data which can be used as a key input to energy conservation, tariff structure and reliability-cost evaluation in power system planning and operation.

\section{References}

[1] Kristina, H. and Eto, J. (2004) Understanding the Cost of Power Interruptions to Electricity Consumers. Ernest Orlando National Laboratory, University of California, Berkeley.

[2] Manikya, R., Prasad, P. and Tulasi, R. (2010) Consumer Outage Cost Evaluation in Electric Power Systems. Journal of Engineering and Applied Sciences, 5.

[3] Snead, B. (2006) Energy Efficiency and Conservation in the Residential, Commercial and Industrial Sectors. Final Report, Kansas State University, Manhattan.

[4] Vivien, F., Jean, P. and Woodon, Q. (2000) Energy Consumption and Income: An Inverted-U at the Household Level. World Bank, Washington DC.

[5] Layton, D.F. (2006) The Cost of Power Interruptions to the Residential Consumers. School of Public Affair, University of Washington, Washington DC, Applications of Simulation Methods in Environmental and Resource Economics.

[6] Benders, R.M. (2006) New Approaches for Household Energy Conservation: In Search of Personal Household Energy Budgets and Energy Reduction Options. Energy Policy, 34, 3612-3622. https://doi.org/10.1016/j.enpol.2005.08.005

[7] McMakin, A.H. (2002) Motivating Residents to Conserve Energy without Financial Incentives. Environment and Behavior Journal, 34, 848-863. https://doi.org/10.1177/001391602237252

[8] Marshall, M. (1987) Social-Psychological Correlates of Household Energy-Conservation Activities. Ph.D. Thesis, Claremont Graduate School, Claremont.

[9] Fuji, E.T. (1989) Model of Household Electricity Conservation Behavior. Land Econ, 60, 340-351. https://doi.org/10.2307/3145710

[10] Yoshiyuki, S. (2007) Evaluation of City-Scale Impact of Residential Energy Conservation Measures Using the Detailed End-Use Simulation Model. Energy, 32, 16171633. https://doi.org/10.1016/j.energy.2007.01.007

[11] Park, H.-C. and Heo, E. (2007) The Direct and Indirect Household Energy Requirements in the Republic of Korea from 1980 to 2000. Energy Policy, 35, 1980-2000. https://doi.org/10.1016/j.enpol.2006.10.002

[12] Ghaddar, N. (1998) Energy Conservation of Residential Buildings in Beirut. International Journal of Energy Research, 22, 523-546. https://doi.org/10.1002/(SICI)1099-114X(199805)22:6<523::AID-ER373>3.0.CO;2$\underline{\mathrm{R}}$

[13] Taniguchi, A., et al. (2007) Effectiveness of Energy Conservation Measures in Residential Sector of Japanese Cities. Proceedings: Building Simulation, 1645-1652.

[14] Xu, P. (1996) A Case Study of Upgrading an Existing Residential Building Relating 
to Energy Conservation in China. Journal of Building, Physics, 20, 116-131. https://doi.org/10.1177/109719639602000204

[15] Abrahamse, W. (2005) A Review of Intervention Studies Aimed at Household Energy Conservation. Journal of Environmental Psychology, 25, 273-291. https://doi.org/10.1016/j.jenvp.2005.08.002

Submit or recommend next manuscript to SCIRP and we will provide best service for you:

Accepting pre-submission inquiries through Email, Facebook, LinkedIn, Twitter, etc. A wide selection of journals (inclusive of 9 subjects, more than 200 journals)

Providing 24-hour high-quality service

User-friendly online submission system

Fair and swift peer-review system

Efficient typesetting and proofreading procedure

Display of the result of downloads and visits, as well as the number of cited articles Maximum dissemination of your research work

Submit your manuscript at: http://papersubmission.scirp.org/

Or contact jpee@scirp.org 